\title{
Factors associated with sleep quality in the elderly receiving chemotherapy ${ }^{1}$
}

Thalyta Cristina Mansano-Schlosser ${ }^{2}$

Maria Filomena Ceolim ${ }^{3}$

Objective: to evaluate the characteristics of sleep and the factors associated with the quality of sleep in elderly patients receiving outpatient chemotherapy treatment. Method: cross-sectional study with 140 elderly patients (51.2\% female, average age 69.8 years) with stage III or stage IV cancer $(67.9 \%)$, undertaken in a university hospital in the state of São Paulo in 2010. The following instruments were used: sociodemographic and clinical characterization questionnaire, validated by specialists; Pittsburgh Sleep Quality Index; Piper Fatigue Scale-reviewed; and a scale for the subjective measurement of pain. Results: the majority of the elderly (62.9\%) had a score compatible with poor sleep quality. On average, the duration of sleep was 388.0 minutes, latency was 44.6 minutes and efficiency of $83.8 \%$. Through multiple logistic regression analysis, an increase of $21 \%$ in the probability of having poor sleep quality was observed for each singlepoint increase in the intensity of the pain. Conclusion: nursing interventions aiming to promote better sleep quality for elderly patients with cancer must include measures for pain control.

Descriptors: Sleep; Neoplasms; Antineoplastic Agents; Aged; Nursing.

\footnotetext{
${ }_{1}^{1}$ Paper extracted from Master's Dissertation "Qualidade do sono e fadiga em idosos sob tratamento quimioterápico ambulatorial", presented to Universidade Estadual de Campinas, Brasil. Supported by Fundação de Amparo à Pesquisa do Estado de São Paulo (FAPESP), proceso \# 2009/06606-2.

2 Doctoral Student, Faculdade de Ciências Médicas, Universidade Estadual de Campinas, Brazil.

3 PhD, Professor, Faculdade de Ciências Médicas, Universidade Estadual de Campinas, Brazil.
} 


\section{Fatores associados à qualidade do sono de idosos submetidos à quimioterapia}

Objetivo: avaliar as características do sono e os fatores associados à qualidade do sono de pacientes idosos, submetidos ao tratamento quimioterápico ambulatorial. Método: estudo transversal, com 140 pacientes idosos (51,2\% do sexo feminino, média de idade 69,8 anos), com câncer em estádio III ou IV $(67,9 \%)$, conduzido em um hospital universitário do Estado de São Paulo, em 2010. Utilizaram-se os instrumentos: questionário de caracterização sociodemográfica e clínica, validado por especialistas; Índice de Qualidade do Sono de Pittsburgh; Escala de Fadiga de Piper-revisada; Escala de Mensuração Subjetiva de Dor. Resultados: a maioria dos idosos $(62,9 \%)$ apresentou pontuação compatível com má qualidade do sono. Em média, a duração do sono foi de 388,0 minutos, latência de 44,6 minutos e eficiência, $83,8 \%$. À análise de regressão logística múltipla observou-se aumento de $21 \%$ da probabilidade de apresentar má qualidade do sono a cada acréscimo de um ponto na intensidade da dor. Conclusão: intervenções de enfermagem, visando promover melhor qualidade do sono aos pacientes idosos com câncer, devem agregar medidas para controle da dor.

Descritores: Sono; Neoplasias; Agentes Antineoplásicos; Idoso; Enfermagem.

\section{Factores asociados a la calidad del sueño de mayores sometidos a la quimioterapia}

Objetivo: evaluar las características del sueño y los factores asociados a la calidad del sueño de pacientes mayores sometidos al tratamiento de quimioterapia de ambulatorio. Método: estudio transversal con 140 pacientes mayores ( $51,2 \%$ del sexo femenino, media mayores 69,8 años) con cáncer en estadio III o IV $(67,9 \%)$, acarreado en un hospital universitario de la provincia de São Paulo, en 2010. Se utilizaron los instrumentos: cuestionario de caracterización sociodemográfica y clínica, validado por expertos; Índice de Calidad del Sueño de Pittsburgh; Escala de Fatiga de Piper-revisada; Escala de mensuración subjetiva de dolor. Resultados: la mayoría de los mayores $(62,9 \%)$ presentó puntuación compatible con mala calidad del sueño. En media, la duración del sueño fue de 388,0 minutos, latencia de 44,6 minutos y eficiencia, $83,8 \%$. Al análisis de regresión logística múltiple se observó aumento del $21 \%$ de la probabilidad de presentar mala calidad del sueño a cada añadidura de un punto en la intensidad del dolor. Conclusión: intervenciones de enfermería objetivando promover mejor calidad del sueño a los pacientes mayores con cáncer deben agregar medidas para control del dolor.

Descriptores: Sueño; Neoplasias; Agentes Antineoplásicos; Anciano; Enfermería.

\section{Introduction}

Cancer is a major public health problem in developed countries and developing countries, which has deserved the increasing numbers of research projects aiming to achieve better quality and humanization of the care given to people struck by it. It is estimated that in 2020, the number of new cases per year will be approximately 15 million $^{(1)}$.

The aging of the population is also a worldwide phenomenon, in particular regarding the considerable increase in the population aged 70 or over. In 2009, the results of the National Household Sample Survey indicated a total of 11.3 million persons in this age range in $\mathrm{Brazil}^{(2)}$.
Simultaneously, and in part as a consequence of the aging of the population, a change occurred in the profile of the most prevalent illnesses, with the predominance of non-transmissible chronic illnesses, whose incidence and mortality rise in step with increases in the population's average age. The increase in life expectancy does not only raise an individual's exposure to risk factors present in the environment and the duration of this exposure; aging itself allows the appearance of genetic neoplasias whose appearance is late(3).

Cancer alters many aspects of the individual's life, and may bring significant changes to their daily 
life, depending on the extent of impairment of the ability to carry out habitual activities ${ }^{(4)}$. One important consequence of cancer is poor sleep quality, which is currently receiving greater (although still insufficient) attention from researchers, may also contribute to negative changes in quality of life ${ }^{(5)}$. There is a strong association between sleep disturbances and the occurrence of illnesses or death(6).

Sleep is a cyclical physiological process comprising five stages, which may be distinguished by the pattern of the electroencephalogram (EEG), the presence or not of rapid eye movements (REM) and the changes in various physiological variables such as muscle tone and cardio-respiratory pattern. Nocturnal sleep starts with stage I of synchronized sleep, followed after about ten minutes by stage II. After 30 to 60 minutes, slow-wave sleep occurs, which is deeper and comprises stages III and IV. The first episode of active sleep (or REM) takes place 90 minutes after sleep starts, when the first cycle of synchronized sleep-active sleep is completed, which is repeated about five times per night, resulting in a characteristic architecture(7).

In an elderly individual, an important change may be observed in the sleep architecture, with a reduction in the percentage of slow-wave sleep and active sleep. Stage IV is no longer registered, there is a reduction in stage III and an increase in nocturnal awakenings, which brings lower sleep efficiency as a direct consequence, often resulting in impaired quality. There is an increase in the more superficial stages of sleep (I and II), and sleep latency appears not to suffer important changes. Other changes in the sleep-wake cycle also occur, with redistribution of sleep over the 24-hour period, that is, the intrusion of daytime naps and of interruptions of nocturnal sleep, along with phase advance, that is, sleep starts and ends at ever-earlier times. The total duration of nocturnal sleep in healthy elderly individuals seems to be reduced in relation to young adults, although this is still controversial(8).

An aggravating aspect is that sleep disturbances can become chronic in cancer patients, persisting after the end of treatment for the illness. These patients' sleep is potentially affected by various factors, from biochemical alterations associated with the growth of the tumor to the antineoplastic treatments such as chemotherapy, and by some symptoms which frequently accompany cancer, such as pain and fatigue ${ }^{(9)}$.

Fatigue is a prevalent symptom in oncological illness, being presented in among $75 \%$ to $95 \%$ of cancer patients. Fatigue impairs the activities of daily living, limiting them and prejudicing quality of life and impact on sleep quality ${ }^{(10)}$.

Therefore, research on quality of sleep is extremely important but scarce in oncological patients. Thus, the present study aimed to evaluate characteristics of sleep and factors associated with the quality of sleep in elderly persons submitted to chemotherapy treatment. It is expected that this study may bring support for the offering of holistic and quality care for patients submitted to chemotherapy treatment. The detection of sleep disturbances in elderly individuals with cancer should contribute to nursing interventions aimed at minimizing these patients' suffering.

\section{Method}

This is an exploratory and cross-sectional study undertaken in the chemotherapy outpatient center of a university hospital in the state of São Paulo, with cancer patients receiving chemotherapy, in 2010. The inclusion criteria established were: patients aged 60 or over, with a diagnosis of cancer confirmed in the medical charts, and undergoing treatment with chemotherapy. The exclusion criteria were: primary tumor or metastases in the central nervous system, Karnofsky Scale below 60 , within a post-operative period of 30 days, clinical conditions such as mucositis, intense pain, dyspnea, nausea and vomiting, and emotional conditions such as crying, excessive apathy, and aggression.

A sample size of 111 patients was initially estimated, considering: a study in which the correlation coefficient between quality of sleep and fatigue was approximately $0.50^{(11)}$; precision of estimation of 0.3 ; level of significance of $5 \%{ }^{(12)}$. To prevent possible losses and to obtain greater power of analysis, approximately $20 \%$ more cases were added, totaling 140 subjects. A similar proportion of men to women was maintained (52.1\% and $47.9 \%)$.

The study was approved in August 2009 by the Research Ethics Committee of the institution to which the authors were affiliated (Decision CEP 693/2009). A pilot-study was carried out with 28 elderly patients with cancer, in one of the services where data were collected, verifying the good comprehension of the instruments and the study's viability.

The following instruments were used for collecting data:

- Questionnaire for sociodemographic and clinical characterization, devised by the researcher for obtaining the sociodemographic variables (sex, age, marital status) 
and clinical variables (fatigue, related chronic illnesses, pain and its intensity, symptoms, cancer staging, and other treatments apart from chemotherapy). This questionnaire was evaluated by specialists regarding its content and was considered suitable for administration.

- Pittsburgh Sleep Quality Index (PSQI-BR), validated in Brazil(13), which allows the evaluation of the quality and the disturbances of sleep in the period of one month prior to its administration. It contains 19 questions which may be self-administered or posed in interview, grouped into seven components: 1 . Subjective sleep quality, 2. Sleep latency, 3. Duration of sleep, 4. Habitual efficiency of sleep, 5. Sleep disturbances, 6. Use of medications to sleep, 7. Daytime dysfunction. Scoring for each component varies from zero to three points and the global score, obtained by summing the components may vary from zero to 21 points. The higher the value obtained, the worse the evaluation of sleep quality, with the global score of five points constituting the cut-off point permitting one to distinguish between subjects with poor quality of sleep and sleep disturbances and those with good sleep quality ${ }^{(13)}$.

- Piper Fatigue Scale-reviewed: a multidimensional self-report instrument for evaluating fatigue, validated

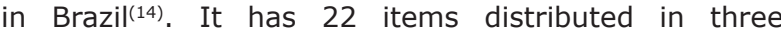
dimensions: Behavioral, related to functional ability; Affective, which seeks to find the meaning attributed to the fatigue; Sensory/psychological, which evaluates emotional and cognitive components and components of self-perception, in the presence of fatigue.

Data collection was undertaken in the outpatient centers in the above-mentioned hospital between August and December 2010. During the infusion of the chemotherapy, the elderly patients were invited by the researcher to participate in the study, respecting the inclusion and exclusion criteria. The patients signed the terms of Free and Informed Consent after reading them and accepting to participate in the study. There was an interruption of 15 days due to the starting of Brazilian daylight saving time, as this can provoke temporary changes in the quality and characteristics of sleep.

The data obtained was codified and typed into an electronic spreadsheet and analyzed with the SPSS software (version 17.0) and the SAS (version 9 1.3, SAS Institute Inc., Cary, NC, USA, 2002-2003).

The sociodemographic and clinical data, as well as the data referent to the characteristics and quality of sleep, were analyzed by means of descriptive statistics. The variables considered to be possible factors associated with poor sleep quality were analyzed using Spearman's Rank Correlation test and the MannWhitney test, due to the distribution being different to normal, according to the Kolmogorov-Smirnov test. Univariate logistic regression was also undertaken, and, following that, the variables with values of $\mathrm{p} \leq$ 0.20 were tested in a multiple logistic regression model, with stepwise criteria.

\section{Results}

The population was characterized by a slight predominance of women (52.1\%). Age varied from 60.2 to 90.3 years, with an average of 69.8 (standard deviation of 6.9 ) years and a median age of 68.3. Elderly married patients were more common (66.4\%), as well as those with four to eight years of schooling (42.9\%), retired and inactive (84.3\%), with beliefs or a religion $(95.7 \%)$ and receiving up to five minimum salaries $(88.6 \%)$ as their individual income.

The majority of the subjects (46.4\%) mentioned one to three chronic illnesses, with arterial hypertension standing out (41.4\%). Use of medications was referred to by $42.9 \%$. The presence of pain was referred to by $51.4 \%$ and its intensity varied from zero to ten points, with an average of 3.7 (standard deviation 4.2) and median of 2.0. A considerable proportion of the elderly patients $(22.1 \%)$ mentioned pain of the maximum intensity, that is, grade ten. The most frequent symptoms were intense thirst $(66.4 \%)$, dry mouth (66.4\%) and nausea $(54.3 \%)$

The most frequent diagnoses were tumors of the digestive system (52.8\%) and breast $(52.1 \%)$, diagnosed, on average, 2.6 years previously (standard deviation 3.4 years), with a median of 1.4 years, varying from one month to 16.5 years. Staging III and IV were observed in $67.9 \%$ of the subjects. The majority were undergoing or had undergone radiotherapy $(52.1 \%)$ and had had surgery related to the tumor (73.6\%) more than 30 days previously. It was ascertained that $62.9 \%$ of the elderly patients had poor quality sleep according to the classification obtained with the PSQI. However, in the responses to the component Subjective Sleep Quality, 75\% of all the elderly patients responded that it was good or very good. 
Table 1 - Statistics of sleep characteristics according to the responses to the PSQI $(n=140)$. Campinas, São Paulo, Brazil, 2010

\begin{tabular}{lcccc}
\hline Sleep characteristics & Average & Standard deviation & Median & Minimum \\
\hline Time - lying down & $21 \mathrm{~h} 17 \mathrm{~min}$ & $01 \mathrm{~h} 23 \mathrm{~min}$ & $21 \mathrm{~h} 00 \mathrm{~min}$ & $17 \mathrm{~h} 00 \mathrm{~min}$ \\
Time - waking up & $05 \mathrm{~h} 16 \mathrm{~min}$ & $01 \mathrm{~h} 47 \mathrm{~min}$ & $05 \mathrm{~h} 30 \mathrm{~min}$ & $23 \mathrm{~h} 00 \mathrm{~min}$ \\
Latency of sleep & $44.6 \mathrm{~min}$ & $43.5 \mathrm{~min}$ & $30.0 \mathrm{~min}$ & $0.0 \mathrm{~min}$ \\
Duration of sleep & $388.0 \mathrm{~min}$ & $112.0 \mathrm{~min}$ & $420.0 \mathrm{~min}$ & $120.0 \mathrm{~min}$ \\
Time spent in bed & $480.0 \mathrm{~min}$ & $120.0 \mathrm{~min}$ & $480.0 \mathrm{~min}$ & $120.0 \mathrm{~min}$ \\
Habitual efficiency of & $83.8 \%$ & $21.4 \%$ & $85.0 \%$ & $18.0 \mathrm{~min}$ \\
sleep* & & & $750.0 \mathrm{~min}$ \\
\hline
\end{tabular}

*value of efficiency of sleep is obtained by dividing the time of 'hours of sleep' estimated by the subject by the number of hours spent in bed, calculated based on the responses about times of lying down and waking up.

The global average score of 7.7 points (standard deviation 4.1, median 7.0 points) was indicative of poor quality sleep. The following components received the higher scores, indicative of worse evaluation: Sleep disturbances, average of 1.7 points (standard deviation 0.6 , median 2.0 points), and Latency for sleep, average of 1.3 points (standard deviation 1.1, median 1.0 point). The lowest score was for the component Use of medications to sleep, with 0.6 points on average (standard deviation 1.0, median 0.0).

It was observed that $48.6 \%$ mentioned taking more than 30 minutes to fall asleep, $30.7 \%$ slept five hours or less per night, and $8.6 \%$ slept nine hours or more. The majority (80\%) had sleep efficiency below $84 \%, 67.9 \%$ denied using medications to get to sleep, and $52.8 \%$ had daytime dysfunction at least once a week.

The detailed analysis of the factors which contributed to the component Sleep disturbances is presented in Table 2, with the need to get up to go to the bathroom (83.6\%) and waking up in the middle of the night or very early in the morning $(47.9 \%)$ standing out.

Table 2 - Number and percentage of occurrence for the factors which contribute to the componente 'Sleep disturbances'. Campinas, São Paulo, Brazil, 2010

\begin{tabular}{|c|c|c|c|c|}
\hline \multirow{2}{*}{ Factors } & \multicolumn{2}{|c|}{ No times per week } & \multicolumn{2}{|c|}{ Three times per week or more } \\
\hline & $\mathbf{N}$ & $\%$ & $\mathbf{N}$ & $\%$ \\
\hline Unable to fall asleep in up to 30 minutes & 64 & 45.7 & 52 & 37.1 \\
\hline Woke up in the middle of the night or early in the morning & 30 & 21.4 & 67 & 47.9 \\
\hline Needed to get up to go to the bathroom & 4 & 2.9 & 117 & 83.6 \\
\hline Could not breathe comfortably & 121 & 86.4 & 2 & 1.4 \\
\hline Coughed or snored strongly & 58 & 41.4 & 71 & 50.7 \\
\hline Felt too cold & 58 & 41.4 & 70 & 50.0 \\
\hline Felt too hot & 107 & 76.4 & 19 & 13.6 \\
\hline Had bad dreams & 91 & 65.0 & 15 & 10.7 \\
\hline Had pain & 83 & 59.3 & 19 & 13.6 \\
\hline
\end{tabular}

A statistically-significant association was observed between the quality of sleep and fatigue $(p=0.03)$, with a higher proportion of elderly persons who reported absence of fatigue presenting good quality sleep; and also between the quality of sleep and the presence of pain $(p=0.00)$, with a higher proportion of those who reported complaints of pain presenting poor quality sleep. The factors associated with poor quality sleep were identified through a univariate logistic regression analysis (Table 3 ). 
Table 3 - Factors associated with poor quality sleep. Univariate logistic regression analysis $(n=128)$. Campinas, São Paulo, Brazil, 2010

\begin{tabular}{|c|c|c|c|c|}
\hline Variable & Categories & p-value & O.R. ${ }^{\dagger}$ & Cl $95 \%$ O. $R^{\ddagger}$ \\
\hline \multirow{2}{*}{ Fatigue (Piper) } & No fatigue (ref. ${ }^{*}$ ) & - & 1.00 & - \\
\hline & With fatigue & 0.052 & 2.11 & $0.99-4.46$ \\
\hline \multirow{2}{*}{ Sex } & Male (ref.) & - & 1.00 & - \\
\hline & Female & 0.729 & 1.13 & $0.56-2.31$ \\
\hline \multirow{2}{*}{ Marital status } & Other (ref.) & - & 1.00 & - \\
\hline & Married & 0.405 & 0.72 & $0.34-1.55$ \\
\hline \multirow{2}{*}{ Pain } & No (ref.) & - & 1.00 & - \\
\hline & Yes & $<0.001$ & 4.01 & $1.89-8.54$ \\
\hline \multirow{2}{*}{ Chronic illness } & No (ref.) & - & 1.00 & - \\
\hline & Yes & 0.244 & 1.53 & $0.75-3.13$ \\
\hline \multirow{2}{*}{$\begin{array}{l}\text { Radiotherapy: current or } \\
\text { previous }\end{array}$} & No (ref.) & - & 1.00 & - \\
\hline & Yes & 0.764 & 0.90 & $0.44-1.83$ \\
\hline \multirow{2}{*}{ Previous surgery } & No (ref.) & - & 1.00 & - \\
\hline & Yes & 0.470 & 1.36 & $0.59-3.15$ \\
\hline \multirow{2}{*}{ Staging } & Stages I or II (ref.) & - & 1.00 & - \\
\hline & Stages III or IV & 0.092 & 2.00 & $0.89-4.46$ \\
\hline Intensity of pain & Continuous variable & $<0.001$ & 1.21 & $1.09-1.34$ \\
\hline
\end{tabular}

*Ref.: level of reference.

+ OR (Odds Ratio) $=$ Ratio of risk for poor quality sleep ( $n=50$ with good quality sleep and $n=78$ with poor quality sleep).

$\neq C I$ $95 \%$ OR $=95 \%$ Confidence Interval for the risk ratio.

The intensity of the pain was the only variable which remained in the final model of multiple logistic regression. For each increase of one (1.0) point in the intensity of pain, there was an increase of $21 \%$ in the probability of presenting poor quality sleep (Table 4 ).

Table 4 - Factors associated with poor quality sleep. Multiple logistic regression analysis $(n=128)$. Campinas, São Paulo, Brazil, 2010

\begin{tabular}{lcccc}
\multicolumn{1}{c}{ Parameters } & Coefficients & Standard error & p-value & O.R.* $^{*}$ \\
\hline Intercept & -0.0856 & 0.228 & & \\
Intensity of the pain & 0.1937 & 0.051 & $<0.001$ & 1.21 \\
\hline
\end{tabular}

* OR (Odds Ratio) = Ratio of risk of poor quality sleep; ( $n=50$ with good quality sleep and $n=78$ with poor quality sleep).

+ CI $95 \%$ OR $=95 \%$ Confidence Interval for the risk ratio.

\section{Discussion}

The sociodemographic characteristics found were similar to those for the Brazilian population aged 60 years and over, except for the proportion of retired persons, which is $57.9 \%$ in $\mathrm{Brazil}^{(2)}$. It must be taken into account that cancer is a disease which frequently leads to early withdrawal from work activities, contributing to explain this divergent percentage.

Aging brings with it the presence of chronic diseases and, as expected, nearly half of the subjects mentioned to arterial hypertension. In the elderly population in Brazil in general, arterial hypertension is found in $59.3 \%{ }^{(2)}$. It is important to stress that, in caring for the cancer patient, one should not neglect the presence of comorbidities.

Sleep alterations have been described in the literature as frequent in patients with cancer. In the present study, $62.9 \%$ of the elderly patients have poor quality sleep, according to the PSQI. Other studies using this instrument found the following percentages: $52 \%$ in adult women with gynecological or breast cancer ${ }^{(15)}$; $52 \%$ of adult patients with lung cancer $^{(16)} ; 56.6 \%$ of elderly patients who survived lung cancer $^{(17)}$; and $73.9 \%$ of adults who had undertaken oncological surgery ${ }^{(18)}$.

The poor quality sleep of the elderly patients is also evidenced by the global average PSQI score, of 7.7 points. Other studies obtained values which indicate poor sleep quality: 6.3 points in elderly survivors of lung cancer $^{(17)} ; 6.8$ points in middle-aged adults with lung cancer, undergoing chemotherapy(16). Other authors found even higher scores (12.0 points) in adults with advanced cancer(19). It may be observed that all point, consistently, to poor sleep quality in these people. The importance of evaluating each component of the PSQI 
separately is emphasized, the better to analyze the impaired aspects of sleep in elderly persons with cancer.

It was ascertained that although $62.9 \%$ of the elderly received a global score indicative of poor quality sleep, $75 \%$ of all of them subjectively evaluated the quality of sleep as good or very good. This finding is congruent with that of another study, in which $74.7 \%$ of elderly lung cancer survivors classified their sleep quality as good or very good, while $56.6 \%$ of the total obtained a score indicating poor quality sleep on the $\mathrm{PSQI}^{(17)}$. It is very common for the elderly to complain of sleep disturbances while appearing to recognize them as a "natural" part of aging.

It was the component 'Sleep disturbances' which obtained the highest score of all, it standing out that the aspects linked to this component are those which most contribute, according to the literature, to poor quality sleep in the elderly ${ }^{(8)}$. Among these aspects, one can stress the need to get up during the night to go to the bathroom, early waking, and waking up in the middle of the night and having difficulty getting back to sleep ${ }^{(20)}$. Other authors also noticed that the component 'Sleep disturbances' had the highest score in relation to the other components, in adults with cancer ${ }^{(21)}$ and in elderly survivors of lung cancer(17).

The component 'Use of medications to sleep' obtained the lowest score, it being observed that $13.5 \%$ of the elderly patients use these medications regularly. However, $25 \%$ of the total of the elderly described the subjective quality of sleep as bad or very bad, and $62.9 \%$ obtained a score compatible with poor quality sleep. This data is congruent with that from another study undertaken in adults with lung cancer ${ }^{(16)}$, in which $50 \%$ reported poor quality sleep and only $13 \%$ used medications to sleep. The findings suggest that the sleep disturbances, in these subjects, could pass unnoticed and, in this way, not be appropriately treated. In addition, the way of investigating sleep quality may underestimate the importance of problems related to it. One example of this is the use of a single question, to know "what is the quality of your sleep like?", without detailing other aspects which may compromise the quality of sleep in the elderly.

Other authors have found sleep length similar to that of the present study, of 388 minutes (six hours and twenty-eight minutes). In one study of adults undergoing chemotherapy for lung cancer, the average duration of sleep was 404 minutes (six hours and fortyfour minutes) ${ }^{(16)}$ and, in elderly survivors of lung cancer, it was 390 minutes (six hours and thirty minutes) on average $^{(17)}$. The findings showed that $30.7 \%$ of the elderly slept five hours or less per night, and that $8.6 \%$ slept nine hours or more. In this way, the reduction in hours of sleep or their excess add a possible risk factor for worsening of health conditions of the elderly person with cancer.

A sleep efficiency of below $85 \%$ was found in half of the elderly persons studied, with an average of $83.8 \%$. In the literature, elderly survivors of lung cancer obtained lower values, $78.3 \%{ }^{(17)}$, and adults with lung cancer had average values similar to those of the present study, $82.8 \%$, during chemotherapy treatment ${ }^{(16)}$. The efficiency of the sleep is directly linked to the feeling of rest during the day and, when low, may impair the quality of the wakefulness.

The episodes of pain were related to the sleep disturbances for $13.6 \%$ of this study's elderly patients while, in another investigation, this proportion was $9 \%(16)$.

However, the fact of having pain was shown to be a factor associated with poor sleep in this study, in that the addition of one point on the pain scale increases by $21 \%$ the probability of having poor quality sleep. Furthermore, a significant number of elderly (22.1\%) reported maximum intensity pain on the evaluation scale.

Pain is one of the main problems facing cancer patients, and is present in $30 \%$ of patients at time of diagnosis, increasing to 65 to $85 \%$ with disease progression, and to $90 \%$ among patients hospitalized with cancer(22).

It is relevant therefore that nurses should know how to appropriately identify pain, evaluating it in a systematic way and giving the due importance to its frequency and significant impact on the person with cancer(23). However, a previous study identified a lack of information among the nurses about the results of methods of control of chronic pain, due to the inadequacy of their training(23). On the other hand, the informants behave as if the pain were part of the illness and treatment, as a natural symptom ${ }^{(23)}$.

There is a complex relationship between sleep problems and pain, as these symptoms can be a consequence of the cancer, or even constitute causes or consequences one of the other(24). To this one can add the poor quality of the elderly person's sleep, which is often also seen as a natural part of aging. Another recent Brazilian study showed results which corroborate this statement ${ }^{(20)}$. The present investigation adds, as a relevant finding, that the association existing between 
poor quality sleep and pain is not perceived by the majority of the patients.

Therefore, there is an evident concern with factors associated with poor sleep quality in cancer patients, emphasizing the need to evaluate them and treat them together, rather than in isolation.

\section{Conclusions}

The evaluation of 140 elderly cancer patients receiving chemotherapy treatment allowed it to be evidenced that $62.9 \%$ had poor quality sleep, the probability of which increases significantly with the intensity of pain. The recognition of specific factors which lead to disturbance of nocturnal sleep is fundamental to direct the interventions and guidance to be planned and implemented by the health care professionals.

It is noteworthy that comparison with other studies is limited by the difficulty in obtaining studies whose data set is composed exclusively of elderly cancer patients. The majority of research projects used for data comparison were undertaken with adult individuals, whose average age varied at about 50 or 60 years old, with the inclusion of young adults.

In addition, some limitations of this study must be observed, such as the fact it is a cross-sectional study. The clinical variables focused on the physical component, although the literature mentions, for cancer patients, the relevancy of psychological variables, such as the presence of depression, which interfere in sleep quality. Another limitation is the non-inclusion, in this study, of variables which could lead to good quality sleep. Further, sleep quality was evaluated through self-reporting without the use of methods such as polysomnography and actigraphy. Such limitations may be overcome in future studies.

The study's relevance is in the data set belonging in the Brazilian context. It is important to place it as research in evidence in clinical nursing practice so that it may create an opportunity for the patients to report complaints related to sleep. These complaints must be studied and identified as a nursing diagnosis, such that individualized care plans may be implemented for cancer patients receiving chemotherapy treatment.

\section{References}

1. Ministério da Saúde. Secretaria de Atenção à Saúde. Instituto Nacional de Câncer. Coordenação de Prevenção e Vigilância de Câncer. Estimativas 2010: Incidência de Câncer no Brasil. Rio de Janeiro: INCA; 2009.
2. Instituto Brasileiro de Geografia e Estatística (IBGE). Síntese de Indicadores Sociais: Uma Análise das Condições de Vida da População Brasileira. Estudos e Pesquisas Informação Demográfica e Socioeconômica. Brasil - 2010. [acesso 22 fev 2011]. Disponível em: http://www.ibge.gov.br/home/estatistica/ populacao/condicaodevida/indicadoresminimos/ sinteseindicsociais2010/SIS_2010.pdf

3. Nordhturft $V$, Schneider JM, Hebert $P$, Bradham DD, Bryant $M$, Phillips $M$, et al. Chronic disease selfmanagement: improving health outcomes. Nurs Clin North Am. 2000;35(2):507-17.

4. Michelone APC, Santos VLCG. Quality of life of cancer patients with and without an ostomy. Rev. Latino-Am. Enfermagem. 2004;12(6):34-47.

5. Lee K, Cho M, Miakowiski C, Dodd M. Impaired sleep and rhythms in persons with cancer. Sleep Med Rev. 2004; 8(3):199-212.

6. Corrêa K, Ceolim MF. Qualidade do sono em pacientes idosos com patologias vasculares periféricas. Rev Esc Enferm USP. 2008;42:3-7.

7. Fernandes RMF. O sono normal. Medicina. 2006;39(2):157-68.

8. Ohayon MM, Carskadon MA, Guilleminault C, Vitiello MV. Meta-Analysis of Quantitative Sleep Parameters From Childhood to Old Age in Healthy Individuals: Developing Normative Sleep Values Across the Human Lifespan. Sleep. 2004;27:(7):1253-70.

9. Roscoe AJ, Kaufman ME, Matteson-Rusby SE, Palesh OG, Ryan JL, Kohli S, et al. Cancer-Related Fatigue and Sleep Disorders. Oncologist. 2007;12(1):35-42.

10. Coelho FMR, Sawada NO. Fatigue in patients with laryngeal cancer. Rev. Latino-Am. Enfermagem. 1999;7(5):103-10.

11. Beck SL. Pain, Sleep Disturbance, and Fatigue in Patients With Cancer: Using a Mediation Model to Test a Symptom Cluster. Oncol Nurs Forum. 2005;32(3):242.

12. Bonett, DG; Wright TA. Sample size requirements for estimating Pearson, Kendall and Spearman correlations. Psychometrika. 2000;65:23-8.

13. Bertolazi NA, Fagondes SC, Hoff LS, Dartora EG, Miozzo ICS, Barba MEF, et al. Validation of the Brazilian Portuguese version of the Pittsburgh Sleep Quality Index. Sleep Med. 2011;12:70-5.

14. Mota DD, Pimenta CA, Piper BF. Fatigue in Brazilian cancer patients, caregivers, and nursing students: a psychometric validation study of the Piper Fatigue ScaleRevised. Support Care Cancer. 2009;17(6):645-52.

15. Furlani R, Ceolim MF. Sleep quality of women with gynecological and breast cancer. Rev. Latino-Am. Enfermagem. 2006;14(6):812-79. 
16. Chen $\mathrm{ML}$, Yu CT, Yang $\mathrm{CH}$. Sleep disturbances and quality of life in lung cancer patients undergoing chemotherapy. Lung Cancer. 2008;62:391-400.

17. Gooneratne NS, Dean GE, Rogers AE, Nkwuo, JE, Coyne, JC, Kaiser, LR. Sleep and quality of life in long-term lung cancer survivors. Lung Cancer. 2007;58:403-10.

18. Barichello E, Sawada NO, Sonobe HM, Zago MMF.Quality of sleep in postoperative surgical oncologic patients. Rev. Latino-Am. Enfermagem. 2009;17(4):481-4.

19. Mystakidou K, Parpa E, Tsilika E, Pathiaki M, Patirak E, Galanos A, et al. Sleep quality in advanced cancer patients. J Psychosom Res. 2007;62:527-33.

20. Costa SV, Ceolim MF, Neri AL. Problemas de sono e suporte social: estudo multicêntrico Fragilidade em Idosos Brasileiros. Rev. Latino-Am. Enfermagem 2011;19:(4):920-7 [acesso 28 ago 2012]. Disponível em: http://www.scielo.br/pdf/rlae/v19n4/pt_10.pdf

21. Beck SL, Schwartz AL, Towsley G, Dudley W, Barsevick A. Psychometric Evaluation of the Pittsburgh Sleep Quality Index in Cancer Patients. J Pain Symptom Manage. 2004;27(2):140-8.

22. Eyigor S, Eyigor C, Uslu R. Assessment of pain, fatigue, sleep and quality of life (QoL) in elderly hospitalized cancer patients. Arch Gerontol Geriatrics. 2010;51(3):57-61.

23. Silva LMH, Zago MMF. The care to cancer patients with chronic pain in the view of nurses. Rev. Latino-Am. Enfermagem. 2001;9:(4) 44-9.

24. Stepanski EJ, Walker MS, Schwartzberg LS, Blakely J, Ong JC, Houts AC. Trouble Sleeping, Depressed Mood, Pain and Fatigue in Cancer Patients. J Clin Sleep Med. 2009;5(2)132-6. 